Int. J. Electrochem. Sci., 13 (2018) 9888 - 9904

\title{
Inhibitory Effect of Pinus massoniana Needle Extract on Corrosion of Q235 Steel in Hydrochloric Acid Medium
}

\author{
Xia Wang ${ }^{*}$, Shuai-fei Ren, Dai-xiong Zhang, Huan Jiang, Yue Gu \\ School of Material Science and Engineering, Southwest Petroleum University, Chengdu Sichuan \\ 610500, China \\ *E-mail: duh1478@163.com
}

doi: $10.20964 / 2018.10 .31$

Received: 25 May 2018 / Accepted: 11 July 2018 / Published: 1 September 2018

\begin{abstract}
An extract of Pinus massoniana needles(PMNE) was obtained by soaking. The inhibitory effect of PMNE on the corrosion of Q235 carbon steel in $1 \mathrm{~mol} \cdot \mathrm{L}^{-1} \mathrm{HCl}$ was investigated by the weight loss method, potentiodynamic polarization curves, electrochemical impedance spectroscopy and a quantum chemical study. The results indicated that PMNE was an efficient inhibitor with a corrosion inhibition efficiency of 95\%. The equilibrium constant, free energy of adsorption, adsorption enthalpy were calculated and discussed. Thermodynamic analysis revealed that the adsorption of effective inhibitory constituents of PMNE on the Q235 steel surface was in accordance with the Langmuir isotherm equation, and was classed as physical adsorption. Polarization curves, and electrochemical impedance spectroscopy demonstrated that the corrosion inhibitor was a mixed inhibitor. A protective film of PMNE on the Q235 steel surface was investigated using scanning electron microscopy. Quantum chemical parameters were determined within the framework of the density functional theory .
\end{abstract}

Keywords: Pinus massoniana needle; plant-derived corrosion inhibitor; Q235 steel; electrochemical impedance spectroscopy; quantum chemical parameter

\section{$\underline{\text { FULL TEXT }}$}

(C) 2018 The Authors. Published by ESG (www.electrochemsci.org). This article is an open access article distributed under the terms and conditions of the Creative Commons Attribution license (http://creativecommons.org/licenses/by/4.0/). 